\title{
Mengenal Sejarah dan Perkembangan Topeng Sidakarya
}

Oleh:

\author{
Putu Melani Chandra Dewi (1704071005), I Putu Putrayana Wardana \\ $\underline{\text { Putu_melani18@gmail.com, putra.yana@undiksha.ac.id }}$
}

\section{Pendahuluan}

Pulau Bali yang dikenal dengan sebutan Pulau Dewata, Pulau Seribu Pura dan Bali Dwipa. Bali yang sangat terkenal di seluruh Indonesia dan bahkan terkenal di seluruh dunia akan keindahan alam dan dengan seni dan kebudayaannya yang unik tentunya menjadi destinasi wisata manca negara. Dari kesenian dan kebudayaan yang ada di Bali menjadikan Bali mempunyai daya tarik tersendiri yang membuat wisatawan datang ke Bali.

Masyarakat bali memiliki bentuk seni pertunjukan berupa Tari Topeng yang dapat menarik perhatian para wisatawan Tari Topeng tidak sekedar berfungsi sebagai hiburan, namun sebagian di antaranya menjadi pelengkap dalam sebuah ritual keagamaan biasnya di tarikan pada saat upacaya "yadnya” nanum Tari Topeng tidak hanya hadir dalam prosesi keagamaan di halaman utama Pura namun juga berfungsi dalam upacara perkawinan, potong gigi, hingga upcara ngaben. Tarian Topeng ada sejak abad ke-17, Tari Topeng merupakan suatu bentuk Tari dan juga berisi drama dimana penarinya menggunakan Topeng dan menampilkan cerita-cerita lama, yang biasanya berkisah tentang Raja dan Rahlawan pada jaman dahulu, Tarian Topeng dengan puncak penampilan figur Topeng berkarakter angker yang disebut tupeng sidakarya.

Dalam Tari Topeng, setiap penari tampil dengan busana khusus serta mengenakan topeng, dari topeng yang dikenakan oleh seorang penari tersebut akan menunjukkan tokoh yang diperankannya. Adapun jenis-jenis topeng antara lain 
Topeng keras (sosok petarung), Topeng tua (sosok sesepuh), Topeng bondres (rakyat biasa), dan Topeg ratu (khalangan bangsawan).

Tulisan ini akan membahas tentang Mengenal Sejarah Topeng Sidakarya. Adapun yang di bahas dalam tulisan ini antara lain: (1). mengetahui cerita sejarah Topeng Sidakarya di Bali. (2). perkembangan topeng Sidakarya.

\section{SEJARAH TOPENG SIDAKARYA DI BALI}

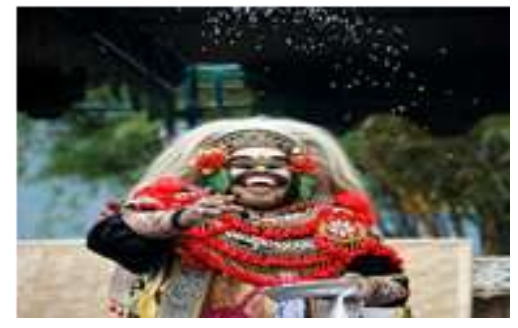

Gambar 1.1 Topeng Sidakarya

(Sumber: www.google.com, 2017)

Di suatu Desa/Daerah yang bernama Keling ada pendeta yang sangat termahsyur tentang kebenaran utama yang mempunyai "Ilmu Kelepasan Jiwa". Disebut Brahmana Keling karena beliau berasal dari Daerah Keling, Jawa Timur. Beliau juga mendirikan pesraman/pertapaan di lereng Gunung Bromo. Brahmana Keling adalah putra dari Danghyang Kayumanis, cucu dari Empu Candra, kumpi dari Mpu Bahula dan cicit dari Empu Beradah. Brahmana Kaling merupakan putra dari Dang Hyang Kayu Manis yang merupakan nabe dari Ida Dalem Waturenggong yang menjadi raja di Bali Yang berkedudukan di Gelgel, Klungkung.

Ketiaka beliau sedang asyik menikmati panorama Selat Bali, datanglah ayah beliau (Dang Hyang Kayu Manis) yang baru datang dari Gelgel, Bali, di mana Keraton Gelgel Klungkung diperintah oleh Dalem Waturenggong. Mendengarkan hal itu, maka Brahmana Kaling segera pergi ke Bali. 
Dikisahkan, Brahmana Kaling pergi ke Bali, sesampai Brahmana Kaling di Keraton Gelgel, Klungkung untuk menemui sang Raja. Sesampai di Keraton Gelgel sangat sepi karena Raja Waturenggong sedang berada di Pura Besakih mempersiapkan pelaksanaan upacara. Brahmana Kaling pun langsung menuju Pura Besakih ingin bertemu dengan saudaranya, Dalem Waturenggong. Sesampai Brahmana kaling di Pura Besakih, Brahmana Kaling disapa para pengayah dan ditanyakan mau bertemu siapa. Brahmana Klaing menjawab ia ingin menemui saudaranya Dalem Waturenggong dan Dang Hyang Nirartha. Para pengayah ragu atas pengakuan Brahmana Kaling, sehingga kedatangannya belum berani disampaikan kepada Raja.

Namun, karena segera ingin bertemu, Brahmana Kaling masuk ke dalam Pura Besakih tanpa dilihat orang. Karena saking lelahnya, beliau menuju pelinggih dan beristirahat sejenak. Tak berselang lama datanglah Dalem Waturenggong dan melihat bahwa ada orang dengan pakaian lusu. Raja akhirnya memanggil prajurit untuk menanyakan siapa gerangan orang tersebut. Prajurit pun melaporkan bahwa orang itu tiada lain Brahmana Kaling.

Sayang sekali Brahmana Kaling tidak diakui sebagai saudara karena melihat pakaiannya yang compang-camping dikira orang gila, bahkan diusir dengan paksa. Raja Dalem Waturenggong kemudian memerintahkan prajurit mengeluarkan Brahmana Kaling dari lingkungan Pura. Brahmana Kaling yang tidak diakui sebagai saudara akhirnya meninggalkan Pura Besakih.

Pada saat itu, Brahmana Klaing sempat mengucapkan Kutuk Pastu yang isinya: Wastu tata astu, karya yang dilaksanakan tan sidakarya (tidak sukses), bumi kekeringan, rakyat kekeringan, sarwa gumatat-gumitit ngrubed. Setelah mengucapkan kutuk tersebut, beliau menuju Desa Sidakarya.

Tidak Berselang lama kutuk yang di ucapkan oleh Brahmana Kaling terbukti. Akhirnya Pulau Bali diserang wabah dan hama. Berkenan dengan bencana ini, Dang Hyang Nirarta menghaturkan upakara untuk memohon keselamatan, tetapi 
permohonan ini tidak berhasil. Pada suatu malam, Dalem Waturenggong bersemedi di Pura Besakih dan mendapatkan petunnjuk Ida Batara bahwa beliau telah berdosa mengusir saudaranya sendiri. Untuk mengembalikan keadaan semula, hanya Brahmana Klaing yang mampu melakukannya. Kemudian Dalem Waturenggong mengutus rakyatnya mencari Brahmana Kaling sampai ketemu. Berangkatlah rombongan penjemput Brahmana Kaling untuk dimohon agar bersedia menemui Dalem Waturenggong. Akhirnya Brahmana Kaling dijumpai di Bandanda Negara yang sekarang disebut Desa Sidakarya dimana pura Mutering Jagat Sidakarya berada. Brahmana kaling bersedia mengembalikan keadaan seperti sedia kala.

Dalem Waturenggong di hadapan para Menteri/Patih/Pre Arya, Dang Hyang Nirarta dan Dalem Sidakarya bersabda: Mulai saat ini dan selanjutnya, bagi Setiap umat Hindu yang melaksanakan karya (Upacara Yadnya) wajib nunas tirta penyida karya, supaya karya (Upacara Yadnya) menjadi Sidakarya. Untuk mengenang jasa Dalem Sidakarya seterusnya dan demi adanya parahyangan tempat nunas tirta Sidakarya bagi umat Hindu Sekitar tahun 1518 M Dalem Waturenggong memerintahkan agar mendirikan Pura Dalem Sidakarya.

Mulai saat itu Dalem Waturenggong memerintahkan seluruh rakyat Bali, untuk suksesnya karya atau upacara yang akan dilaksanakan, agar memohon jatu karya ke Pura Dalem Sidakarya. Di samping itu, pada setiap upacara keagamaan supaya diadakan pertunjukan Topeng Sidakarya, menghaturkan wali Sidakarya sebagai pelegkap upacara penting umat Hindu.

Kutipan dari I Nyoman Kantun, SH MM dan Drs. I Ketut Yadnya. 


\section{PERKEMBANGAN TOPENG SIDAKARYA}

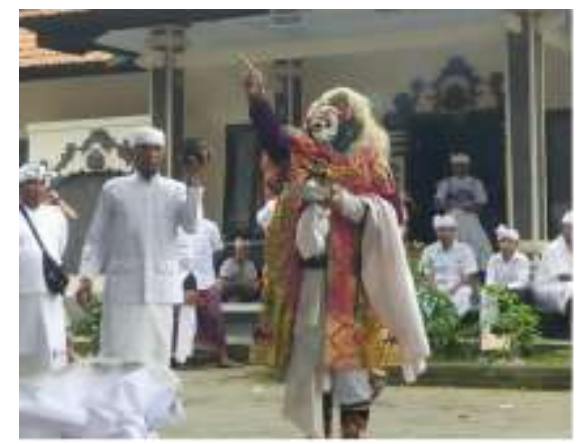

Gambar 1.2 Topeng Sidakarya Di Desa Rianggede

(Sumber : Dokumentasi Pribadi, 11 November 2017)

Saat imi Topeng Sidakarya tetap dilestarikan karena Tari Topeng merupakan pelengkap dari upacara Yadnya di Bali. Di Desa Rianggede, Kabupaten Tabanan, Kecamatan Penebel, Setiap upacara keagamaan terutama dalam tingkatan yang lebih besar, seperti Karya (Upacara Yadnya) Wali Sidakarya tidak dapat dilupakan.

Tari Topeng tampil sebagai pamungkas tari persembahan (wewalen) sebelum acara pemujaan bersama yang dipimpin oleh Sulinggih. Tujuan di Tarikannya Tari Topeng Sidakarya supaya upacara berlangsung hingga selesai dengan baik dan selamat terhindar dari segala mara bahaya. Upacara yadnya yang tidak hanya dipimpin atau dan di puput (diselesaikan) oleh Pendeta (sulinggih) Namun Topeng Sidakarya juga ikut memberi pengukuhan suksesnya sebuah upacara. Pada akhir pertunjukan Topeng Sidakarya secara simbolis peranan Sidakarya menghamburhamburkan uang kepeng dan beras kuning (sekarura) supaya di beri Anugrah kesempurnaan dan Kemakmuran.

\section{PENUTUP}

Kita sebagai generasi muda harus menjaga dan melestarikan kebudayaan yang telah leluhur wariskan kepada kita. Banyak dari budaya-budaya yang diwariskan secara turun temurun yang kini sudah tidak bisa kita jumpai lagi. Terutama Tari Topeng Topeng merupakan warisan leluhur yang sangat penting kita jaga dan 
lestarikan karena Tari Topeng dipercaya oleh umat Hindu sebagai ritual pelengkap upacarayadnya yang dapat membuat upacara tersebut berlangsung dengan lancar.

\section{REFERENSI}

Utama, I Gusti Bagus Rai. 2016. Komplikasi Bali Tempo Dulu. http://tourismbali.files.wordpress.com/2016/03/komplikasi-bali-tempo-dulu.pdf. $\quad 4$ Desember 2017.

Tari Topeng Bali, Seni Tari Tradisional Pulau Dewata.2017. http://tradisitradisional.blogspot.co.id. 4 Desember 2017 